Document downloaded from:

http://hdl.handle.net/10251/155306

This paper must be cited as:

Candu, N.; Man, I.; Andrada, S.; Cojocaru, B.; Coman, SM.; Bucur, C.; Primo Arnau, AM.... (2019). Nitrogen-doped graphene as metal free basic catalyst for coupling reactions. Journal of Catalysis. 376:238-247. https://doi.org/10.1016/j.jcat.2019.07.011

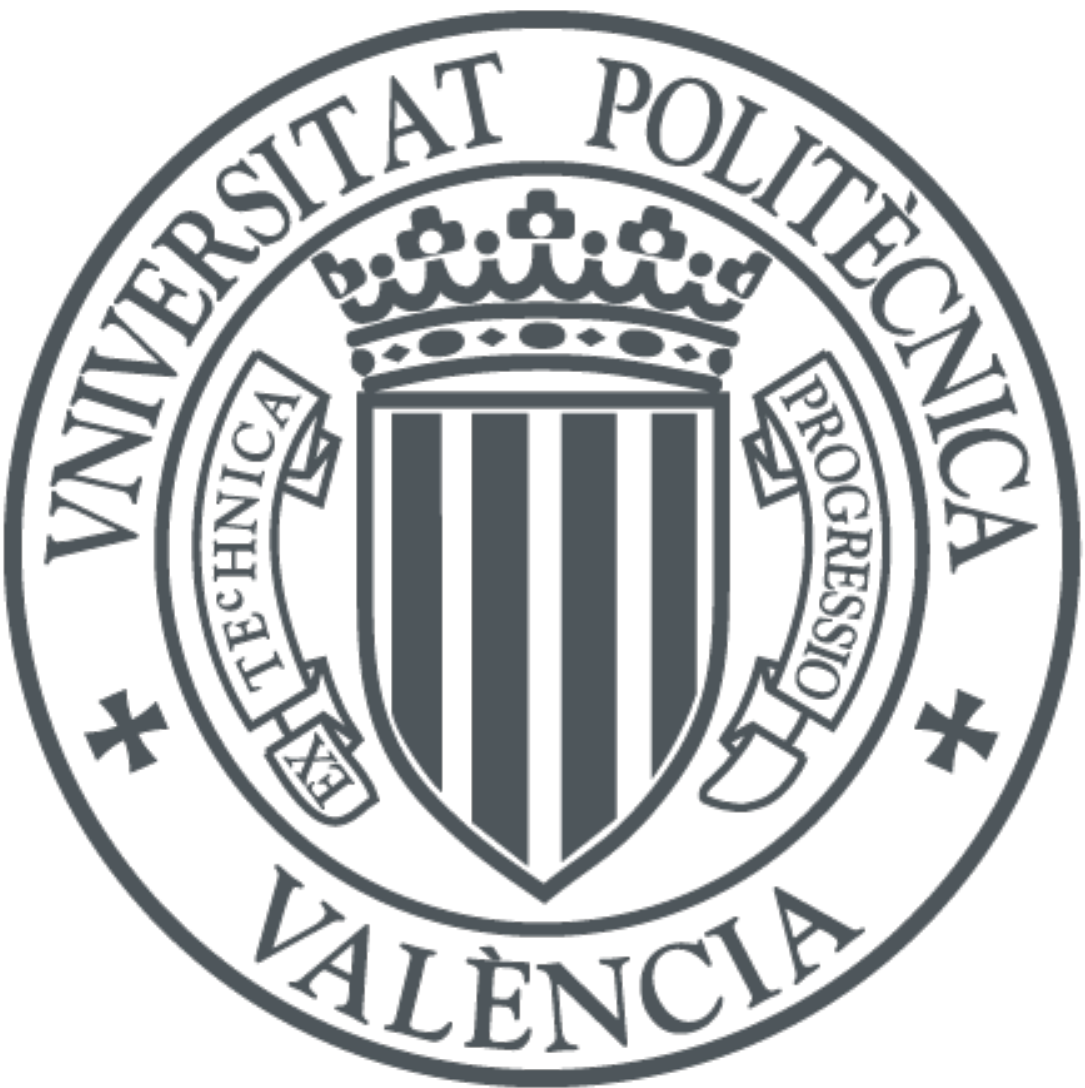

The final publication is available at

https://doi.org/10.1016/j.jcat.2019.07.011

Copyright Elsevier

Additional Information 


\section{Nitrogen-doped graphene as metal free basic catalyst for coupling reactions}

Natalia Candu, + Isabela Man,$\neq$ Andrada Simion, + Bogdan Cojocaru + , Simona M. Coman,+ Cristina Bucur, ${ }^{\&}$ Ana Primo, ${ }^{\S}$ Hermenegildo Garcia,${ }^{{ }^{*}}$ Vasile I. Parvulescu, ${ }^{*}$

${ }^{+}$Department of Organic Chemistry, Biochemistry and Catalysis, University of Bucharest, 4-12 Regina Elisabeta Blv., 030016, Bucharest, Romania E-mail: vasile.parvulescu@chimie.unibuc.ro.

‡ Center of Organic Chemistry "C.D. Nenitescu” of Romanian Academy, Spl. Independentei 202B, sector 6, Bucharest.

\&National Institute of Materials Physics, Department of Surfaces and Interfaces, Atomistilor 405 A, 077125 Magurele-Ilfov, Romania

${ }_{\S}^{\S}$ Instituto Universitario de Tecnologia Quimica Consejo Superior de Investigaciones Científicas, Universitat Politecnica de Valencia, Avda. de los Naranjos s/n, Valencia 46022, E-mail: hgarcia@qim.upv.es.

KEYWORDS graphene, nitrogen doped graphene, Michael reaction, Henry reaction, density functional theory, adsorption energy. 
ABSTRACT N-doped defective graphene $[(\mathrm{N}) \mathrm{G}]$ obtained by pyrolysis at $900{ }^{\circ} \mathrm{C}$ of chitosan contains about $3.7 \%$ of residual $\mathrm{N}$ atoms, distributed as pyridinic, pyrrolic and graphitic $\mathrm{N}$ atoms. It has been found that $(\mathrm{N}) \mathrm{G}$ acts as basic catalyst promoting two classical $\mathrm{C}-\mathrm{C}$ bond forming nucleophilic additions in organic chemistry, such as the Michael and the Henry additions. Computational calculations at DFT level of models corresponding to the various $\mathrm{N}$ atoms leads to the conclusion that $\mathrm{N}$ atoms are more stable at the periphery of the graphene sheets and that $\mathrm{H}$ adsorption on these sites is a suitable descriptor to correlate with the catalytic activity of the various sites. According to these calculations the most active sites are pyridinic $\mathrm{N}$ atoms at zig-zag edges of the sheets. In addition, $\mathrm{N}$ as dopant changes the reactivity of the neighbour $\mathrm{C}$ atoms. Water was found a suitable solvent to achieve high conversions in both reactions. In this solvent the initial distribution of $\mathrm{N}$ atoms is affected due to the easy protonation of the $\mathrm{N}_{\mathrm{Py}}$ to $\mathrm{N}_{\mathrm{PyH}}$ sites. As an effect, $\mathrm{C}$ edge sites adjacent at $\mathrm{N}_{\mathrm{PyH}}$ with an appropriate reactivity towards the $\alpha-\mathrm{C}-\mathrm{H}$ bond breaking are formed. The present results show the general activity of Ndoped graphene as base catalysts and illustrate the potential of carbocatalysis to promote reactions of general interest in organic synthesis.

\section{INTRODUCTION}

Graphene, a single layer of carbon atoms in perfect hexagonal geometry with a uniform sp2hybridized configuration has been considered an excellent suitable support of active nanoparticles due to its high surface area (theoretical value of $2630 \mathrm{~m}^{2} / \mathrm{g}$ ) and strong metalsupport interactions $^{1,2}$. More recently, besides as support of active sites, the use of defective graphenes (Gs) as metal-free catalysts is under intense investigation ${ }^{3-5}$. 
Gs as catalysts allow a certain control of their catalytic properties by varying the density of defects and by doping with different heteroatoms (B, N, O, P and S). The combination of defects and doping allows tailoring the electronic and catalytic properties of Gs through the modulation, for instance, of their acid/base site population and strength distribution ${ }^{6,7}$. Among the various heteroatoms, incorporation of nitrogen into a carbon matrix has attracted a considerable attention as a way to implement in carbon materials active sites for catalysis, electro- and photocatalysis ${ }^{8-}$ 10. Nitrogen atoms in graphene can be, at least, in three different bonding configurations corresponding to quaternary (or graphitic), pyridinic, and pyrrolic N. Among these, the presence of pyridinic and pyrrolic heterocycles inside the graphenic structure should change the basic properties of graphene, nitrogen serving as an electron donor site ${ }^{11-13}$. These properties elicited a considerable interest and were corroborated by the electro-, photo- and catalytic properties of Ndoped graphenes. $\mathrm{N}$ doped carbon materials, like $\mathrm{N}$-containing carbon nanotubes [14, 15], Ndoped carbon materials [16] or mesoporous carbon nitride (MCN) [17] act as effective solid base catalysts for Knoevenagel condensation or transesterification reactions [16-17].

Base catalysis is very important in organic synthesis as there are numerous classical condensation reactions leading to formation of $\mathrm{C}-\mathrm{C}$ bonds involving carbonyl groups that require the use of bases as catalysts. In the vast majority of the cases, the bases used are soluble in the reaction media. However, from the green point of view to minimize liquid wastes and purification steps, it would be important to develop heterogeneous basic catalysts. Among solid, insoluble basic catalysts, certain alkali exchanged zeolites, layered hydrotalcites and alkali-Earth metal oxides are the most frequently used. It would be of large fundamental and applied interest to determine if $\mathrm{N}$-doped graphenes can also be used as basic catalyst and to compare the catalytic performance of these carbocatalysts with that of conventional inorganic bases. 
In the field of basic catalysis, Michael and Henry additions are two important classes of C-C bond forming reactions with large use in organic synthesis [18]. These reactions allow to obtain natural products and complex compounds with biological activity [19,20]. Michael and Henry reactions require basic or acidic catalysts, typically soluble in the reaction medium. However, the use of soluble acid or basic catalysts has associated several drawbacks including the need of neutralization steps during the reaction work-up and the impossibility to reuse the materials. These soluble acids or bases generate residues and undesirable by-products [21-23].

Graphenes present delocalized $\pi$ orbitals which can donate or accept electron density from reagents and substrates adsorbed on their defects (i.e., either the edges of the sheet or the internal carbon vacancies) [24]. In this way, defective and N-doped Gs can, in principle, act as efficient basic catalysts affording the active sites required by the Michael or Henry additions.

Based on these precedents and with the aim to evaluate the catalytic activity of defective Gs in Michael and Henry additions, herein we report the use of N-doped graphene $[(\mathrm{N}) \mathrm{G}]$ as catalyst in such reactions. (N)G samples were prepared by chitosan pyrolysis, a procedure which does not require any catalyst, avoiding in this way the need for nickel and copper metals. Chitosan is a natural polysaccharide of glucosylamine and, during the pyrolytic process, it acts as simultaneous source of $\mathrm{C}$ and $\mathrm{N}$ in the $(\mathrm{N}) \mathrm{G}$ synthesis. The activity of $(\mathrm{N}) \mathrm{G}$ as a base will be rationalized by computational chemistry on a series of models of plausible $\mathrm{N}$ atom on graphene using DFT reactivity descriptors with the aim to correlate the activity of $(\mathrm{N}) \mathrm{G}$ as base with specific $\mathrm{N}$ sites.

\section{EXPERIMENTAL SECTION}


Unless otherwise specified, all chemicals were purchased from Sigma-Aldrich and used without further purification.

\section{Synthesis of $(\mathrm{N}) \mathrm{G}$ catalyst}

Defective N-doped G was obtained starting from commercial chitosan (Aldrich 448869) that was submitted to pyrolysis under an Ar flow $\left(1 \mathrm{ml} \times \mathrm{min}^{-1}\right)$ in an electrical oven heating at $5{ }^{\circ} \mathrm{C} \times \min ^{-1}$ up to $200{ }^{\circ} \mathrm{C}$, maintaining this temperature for $1 \mathrm{~h}$ and subsequently heating at $5{ }^{\circ} \mathrm{C} \times \min ^{-1}$ up to $900{ }^{\circ} \mathrm{C}$, with a resting time of $2 \mathrm{~h}$. After pyrolysis the oven was cooled down to room temperature under Ar flow. The residue was dispersed in MilliQ water by sonication with a tip $(400 \mathrm{~W})$ for $2 \mathrm{~h}$. The remaining, undispersed particles were separated by decantation and the suspension was freeze-dried to obtain $(\mathrm{N}) \mathrm{G}$ as a powder.

\section{(N)G characterization}

Temperature-programmed desorption of $\mathrm{CO}_{2}\left(\mathrm{TPD}-\mathrm{CO}_{2}\right)$ and ammonia (TPD-NH$)_{3}$ were measured with a Micromeritics Chemisorb 2750 instrument. Before measurements, the samples were heated to $150{ }^{\circ} \mathrm{C}\left(20{ }^{\circ} \mathrm{C} \mathrm{min}^{-1}\right)$ in $30 \mathrm{~mL} \times \mathrm{min}^{-1}$ high-purity helium flow. Subsequently, the samples were cooled down to room temperature in helium flow. $\mathrm{CO}_{2}$ adsorption was performed under ambient conditions, saturating the sample for about $60 \mathrm{~min}$ in a flow of $\mathrm{CO}_{2}(30 \mathrm{~mL} \times$ $\left.\min ^{-1}\right)$. Then, the sample was purged in a helium flow until a constant baseline level was attained. Desorption of $\mathrm{CO}_{2}$ was carried out with the linear heating rate $\left(10{ }^{\circ} \mathrm{C} \mathrm{min}^{-1}\right)$ in a flow of helium until $500{ }^{\circ} \mathrm{C} . \mathrm{NH}_{3}$ adsorption was performed similarly after activation of $(\mathrm{N}) \mathrm{G} 150{ }^{\circ} \mathrm{C}(20$ ${ }^{\circ} \mathrm{C} \mathrm{min}^{-1}$ ) in $30 \mathrm{~mL} \times \mathrm{min}^{-1}$ high-purity helium flow, followed by exposure of the sample for about $60 \mathrm{~min}$ to a flow of $10 \%$ ammonia in helium $\left(30 \mathrm{~mL} \times \mathrm{min}^{-1}\right)$. Then, the sample was purged in a helium flow until a constant baseline level was attained. Desorption of $\mathrm{NH}_{3}$ was 
carried out with the linear heating rate $\left(10{ }^{\circ} \mathrm{C} \mathrm{min}^{-1}\right)$ in a flow of helium until $500{ }^{\circ} \mathrm{C}$. Deconvolution of the TPD peaks is automatically provided by the commercial software implemented in the computer controlling the TPD measurements. Attenuated total reflection Fourier transformed infrared (ATR-FTIR) spectra were recorded using a PerkinElmer Spectrum Two spectrometer, having an ATR cell equipped with a diamond plate (Pike Technologies, Madison, WI). The spectra were recorded with a $4 \mathrm{~cm}^{-1}$ resolution and 20 scans. XPS measurements were performed at normal angle emission in a Specs spectrometer, using Al Ka monochromatic radiation $(\mathrm{h} v=1486.7 \mathrm{eV})$ of an X-ray gun, operating with $300 \mathrm{~W}(12 \mathrm{kV} / 25$ $\mathrm{mA}$ ) power. A flood gun with electron acceleration at $1 \mathrm{eV}$ and electron current of $100 \mu \mathrm{A}$ was used in order to avoid charging effects. The energy of photo ejected electrons are measured using a Phoibos 150 analyzer, operating with pass energy of $30 \mathrm{eV}$. The XP spectra were fitted using Voigt profiles combined with their primitive functions, for inelastic backgrounds. The Gaussian width of all lines and thresholds can be considered constant for each spectrum as they should not differ considerably from one spectrum to another, being always in the range of $2 \mathrm{eV}$. The spectra were collected in the energy range corresponding to $\mathrm{C} 1 \mathrm{~s}$ and $\mathrm{O} 1 \mathrm{~s}$ species.

\section{Computational methodology}

DFT calculations were performed using GPAW $[25,26]$ and the atomic simulation environment (ASE) [27]. The core electrons are described by projector augmented wave method (PAW) [28] and the Kohn-Sham valence states are expanded in real space uniform grids. The models used in this study are undoped and nitrogen doped graphene slabs with armchair $(N) G_{a}$

(orthorhombic $29.8 \times 18.015 \times 16 / 26 \AA$ ) and zigzag $(\mathrm{N}) \mathrm{G}_{\mathrm{z}}$ (orthorhombic $17.22 \times 30.73 \times 16 / 26 \AA$ ) structures. The $(\mathrm{N}) \mathrm{G}_{\mathrm{a} / \mathrm{z}}$ were set to be periodic in $\mathrm{X}$ direction, with vacuum separation of $16 \AA$ 
and $26 \AA$ along the $\mathrm{y}$ and $\mathrm{z}$ directions. The $\mathrm{C}$ edges were saturated with H. Different types of doping on both armchair and zigzag graphene slabs $\left((\mathrm{N}) \mathrm{G}_{\mathrm{a}} /(\mathrm{N}) \mathrm{G}_{\mathrm{z}}\right)$ were considered (Figure SI $1)$.

\section{General procedure for the Michael addition}

To a solution of $\beta$-ketoesters as Michael donor $(1 \mathrm{mmol}$ of the corresponding activated methylene reagent) in $8 \mathrm{~mL}$ of solvent (deionized $\mathrm{H}_{2} \mathrm{O}$, ethanol or acetonitrile) was added methyl vinyl ketone (MVK) as Michael acceptor (1.5 mmoles, $0.105 \mathrm{~g})$, base (0.12 mmoles, $\mathrm{NaOH})$ if required, and $5 \mathrm{mg}$ of $(\mathrm{N}) \mathrm{G}$ as catalysts. The resulting mixture was left stirring at room temperature (RT) for $18 \mathrm{~h}$. The reaction mixture was then filtered. If water was used as solvent, the mixture was extracted using ethyl acetate $(3 \times 10 \mathrm{~mL})$ and the combined organic layer was dried over $\mathrm{Na}_{2} \mathrm{SO}_{4}$ and then concentrated. If $\mathrm{EtOH}$ or $\mathrm{CH}_{3} \mathrm{CN}$ were used as solvent the reaction mixture was filtered and concentrated.

Irrespective of reaction procedure, after reaction the catalyst was collected by filtration or was manually removed, and the reaction products were analyzed by GC using a Trace GC Ultra and DSQ equipments with Trace GOLD TG-5SilMS column $(30 \mathrm{~m} \times 0.25 \mathrm{~mm} \times 0.25 \mathrm{~mm})$ and identified by GC-MS (THERMO Electron Corporation instrument), working with a temperature program $\left(50{ }^{\circ} \mathrm{C}, 2 \mathrm{~min}\right)$ to $250{ }^{\circ} \mathrm{C}$ at $10{ }^{\circ} \mathrm{C} / \mathrm{min}$ (holding time $10.00 \mathrm{~min}$ ) for a total run time of $32 \mathrm{~min}$, at a pressure of 0.38 Torr with $\mathrm{He}$ as the carrier gas.

\section{General procedure for the Henry reaction}

Benzaldehyde (0.5 mmoles), nitromethane (10 mmoles) and catalyst were added to a reinforced glass reactor containing a magnetic stirring bar with $3 \mathrm{~mL}$ of solvent (dried isopropyl 
alcohol (IPA) or deionized $\mathrm{H}_{2} \mathrm{O}$ ). The reactor was sealed hermetically. The resulting mixture was stirred for $2-24 \mathrm{~h}$ at room temperature or at $50{ }^{\circ} \mathrm{C}$. The reaction mixture was then filtered, concentrated and silylated.

\section{Product analysis}

Besides GC-MS (THERMO Electron Corporation instrument), identification of the reaction products was based on ${ }^{1} \mathrm{H}$ and ${ }^{13} \mathrm{C}$ NMR spectroscopy using a Bruker Advance III UltraShield $500 \mathrm{MHz}$ spectrometer, operating at $500,13 \mathrm{MHz}$ for ${ }^{1} \mathrm{H}$ NMR or $125,77 \mathrm{MHz}$ for ${ }^{13} \mathrm{C}$ NMR spectroscopy. For ${ }^{1} \mathrm{H}$ NMR spectroscopy, chemical shifts for each peak are reported in ppm using $\mathrm{CDCl}_{3}(\delta: 7.26 \mathrm{ppm})$ as standard and for ${ }^{13} \mathrm{C} \mathrm{NMR}$ spectra, the chemical shifts are reported in the scale relative to the solvent of $\mathrm{CDCl}_{3}(\delta: 77.0 \mathrm{ppm})$ used as an internal reference.

In the case of the Henry addition, the recovered products were silylated (50 $\mu \mathrm{L}$ pyridine, 100 $\mu \mathrm{L}$ BSTFA (N,O-bis(trimethylsilyl) trifluoroacetamide) and TMCS (trimethylchlorosilane as silane agent) before analysis by GC or GC-MS.

\section{Kinetic measurements}

Kinetic measurements have been carried out for the Henry reaction between nitromethane and benzaldehyde in the range from RT till $80{ }^{\circ} \mathrm{C}$ by measuring TOF values for conversions smaller than 30\%. Further, the activation energies have been calculated using the Arrhenius plot [29].

\section{RESULTS AND DISCUSIONS}

\section{Characterization of (N)G}


Nitrogen doped graphene was prepared and exhaustively characterized as described in our previous work [30]. Briefly, single- or few-layers $(\mathrm{N})$ Gs were prepared by pyrolysis of chitosan powders at $900^{\circ} \mathrm{C}$ in the absence of oxygen and without any acid or metal assistance. The carbon residue after the pyrolysis was dispersed in aqueous medium to remove amorphous carbon and heavy particles and the suspended material recovered by freeze-drying (Scheme 1).

The previously reported characterization of the $\mathrm{N}$-doped graphenic materials via transmission optical microscopy, X-ray photoelectron spectroscopy (XPS), Raman spectroscopy, and high resolution transmission electron microscopy (HRTEM) [31] was coincident with the present sample that, according to elemental combustion analysis, contained a $3.7 \%$ of $\mathrm{N}$.

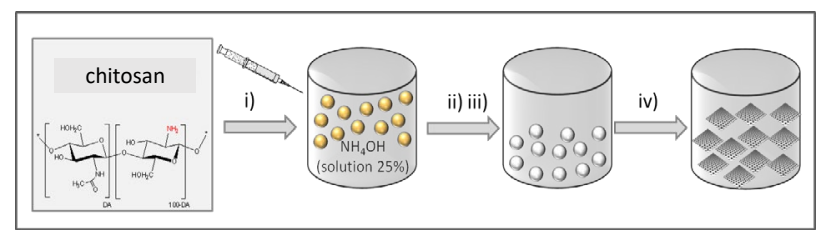

Scheme 1. Illustration of the preparation procedure of dispersible (N)G suspensions by (i) precipitation in basic aqueous solution, ii) ethanol by water exchange, iii) supercritical $\mathrm{CO}_{2}$ drying, iv) pyrolysis of chitosan powders and dispersion of the resulting carbon residue [30].

For the purpose of the present study, the reported characterization [31] was complemented in this work with acid/base titration by thermos-programmed desorption (TPD) with $\mathrm{CO}_{2}$ and $\mathrm{NH}_{3}$, respectively (Figure 1). 


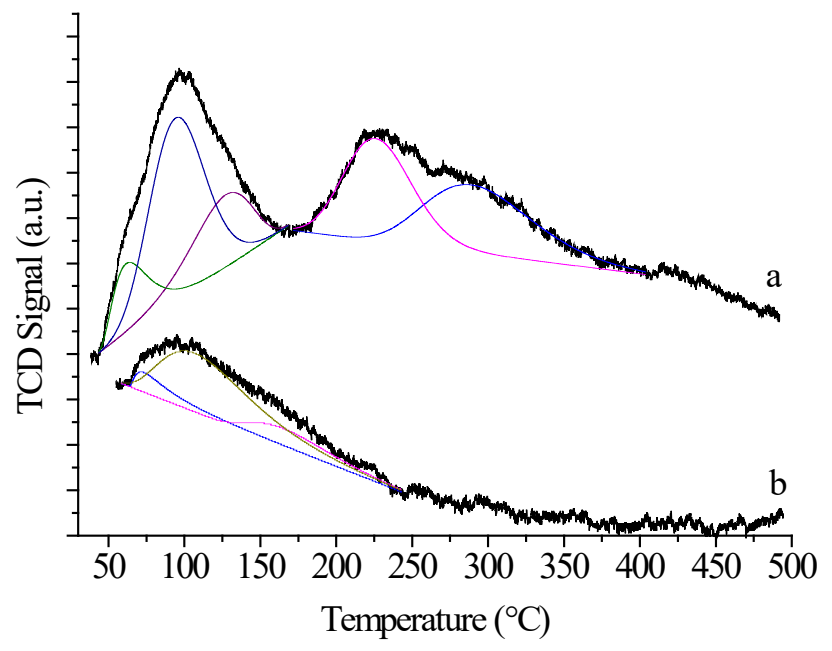

Figure 1. Profiles of $\mathrm{TPD}-\mathrm{CO}_{2}$ (a) and $\mathrm{TPD}-\mathrm{NH}_{3}$ (b) of $(\mathrm{N}) \mathrm{G}$ sample. The plots show deconvolution of the peaks.

In addition, the catalytic activity of N-doped graphene as base was rationalized here by performing computational calculations at DFT level of models. $\mathrm{H}$ adsorption on these sites will be proposed as a descriptor of the catalytic activity as base of the various computed sites.

To determine the distribution of $\mathrm{N}$ atoms present among different families, $(\mathrm{N}) \mathrm{G}$ was analyzed by XPS [32]. This technique confirmed the doping of graphene with $\mathrm{N}$ and the presence of residual $\mathrm{O}$ atoms. Deconvolution of the experimental $\mathrm{C} 1 \mathrm{~s}$ peak of $(\mathrm{N}) \mathrm{G}$ evidenced that $\mathrm{C}$ exists as graphitic $\mathrm{sp}^{2} \mathrm{C}$ atoms $(284-285 \mathrm{eV}, 86 \%)$ and $\mathrm{sp}^{2} \mathrm{C}$ atoms bonded to $\mathrm{N}$ and $\mathrm{O}$ atoms $(285-287 \mathrm{eV}, 14 \%)$, in agreement with literature reports [32] while nitrogen exists as pyridine nitrogen $(398.3 \mathrm{eV}, 25.96 \%)$, pyrrolic nitrogen $(399.8 \mathrm{eV}, 13.54 \%)$, pyridinium nitrogen in polycondensed cycles $(401.2 \mathrm{eV}, 49.01 \%)$ and some pyridine $\mathrm{N}$-oxide and quaternary, graphitic $\mathrm{N}$ atoms $(402.8 \mathrm{eV}, 11.49 \%)$. XPS analysis of $\mathrm{N} 1 \mathrm{~s}$ peak showed that atoms of this element exist merely as pyridinic (binding energy $398.3 \mathrm{eV}$ ) and quaternary nitrogen (binding energy 401.2 eV) species. Pyrrolic and graphitic $\mathrm{N}$ atoms have been as well identified (Figure 2) [33]. 
Analysis of the samples separated after the third, and also fifth cycles, showed no change in the binding energy of the $\mathrm{N}$ 1s levels and also in the relative contribution of the four types of nitrogen components or on the $\mathrm{N} / \mathrm{C}$ ratio.

In agreement with the defective structure of $(\mathrm{N}) \mathrm{G}$, Raman spectra displayed the $\mathrm{G}$ band, at 1590 $\mathrm{cm}^{-1}$, specific of graphene, and a D band, at $1360 \mathrm{~cm}^{-1}$, associated with the presence of nitrogen and defects in the graphene structure [30].

Titration of the total basic and acid sites of $(\mathrm{N})$ Gs catalyst was performed by TPD-CO 2 and TPD$\mathrm{NH}_{3}$ measurements. The amounts of adsorbed $\mathrm{CO}_{2} / \mathrm{NH}_{3}$ are given in Table 1 , while Figure 1 displays the TPD-CO 2 and TPD-NH 3 profiles that give the information of the relative strength of the sites. As Table 1 shows, $(\mathrm{N}) \mathrm{G}$ contains both acid and basic sites, although experimentally the concentration of basic sites is about 22 times higher than the concentration of the acid sites. Comparison of the total basic sites determined by $\mathrm{CO}_{2}$ adsorption with the $\mathrm{N}$ content $(2.4$ $\mathrm{mmol} / \mathrm{g}$ ) shows that only a fraction of about $6.8 \%$ of the $\mathrm{N}$ atoms present in $(\mathrm{N}) \mathrm{G}$ exhibit measurable basicity against $\mathrm{CO}_{2}$.

Table 1. Titration measurements of basic and acid sites by TPD $\mathrm{CO}_{2}$ and $\mathrm{NH}_{3}$ measurements on $(\mathrm{N}) \mathrm{G}$

\begin{tabular}{|c|c|c|}
\hline Peak Number & Temperature at maximum $\left({ }^{\circ} \mathbf{C}\right)$ & Adsorbed probe molecule (mmol/g) \\
\hline CO$_{2}$ adsorption & 61 & 0.0523 \\
\hline 1 & 93 & 0.0142 \\
\hline 2 & 126 & 0.0234 \\
\hline 3 & 225 & 0.0358 \\
\hline 4 & 289 & 0.0374 \\
\hline 5 & TOTAL & $\mathbf{0 . 1 6 3 1}$ \\
\hline \multicolumn{2}{|c|}{$\mathbf{N H}_{3}$ adsorption } \\
\hline 1 & $76 \quad 000$ \\
\hline 2 & 108 & 0.0053 \\
\hline 3 & 164 & 0.0014 \\
\hline
\end{tabular}



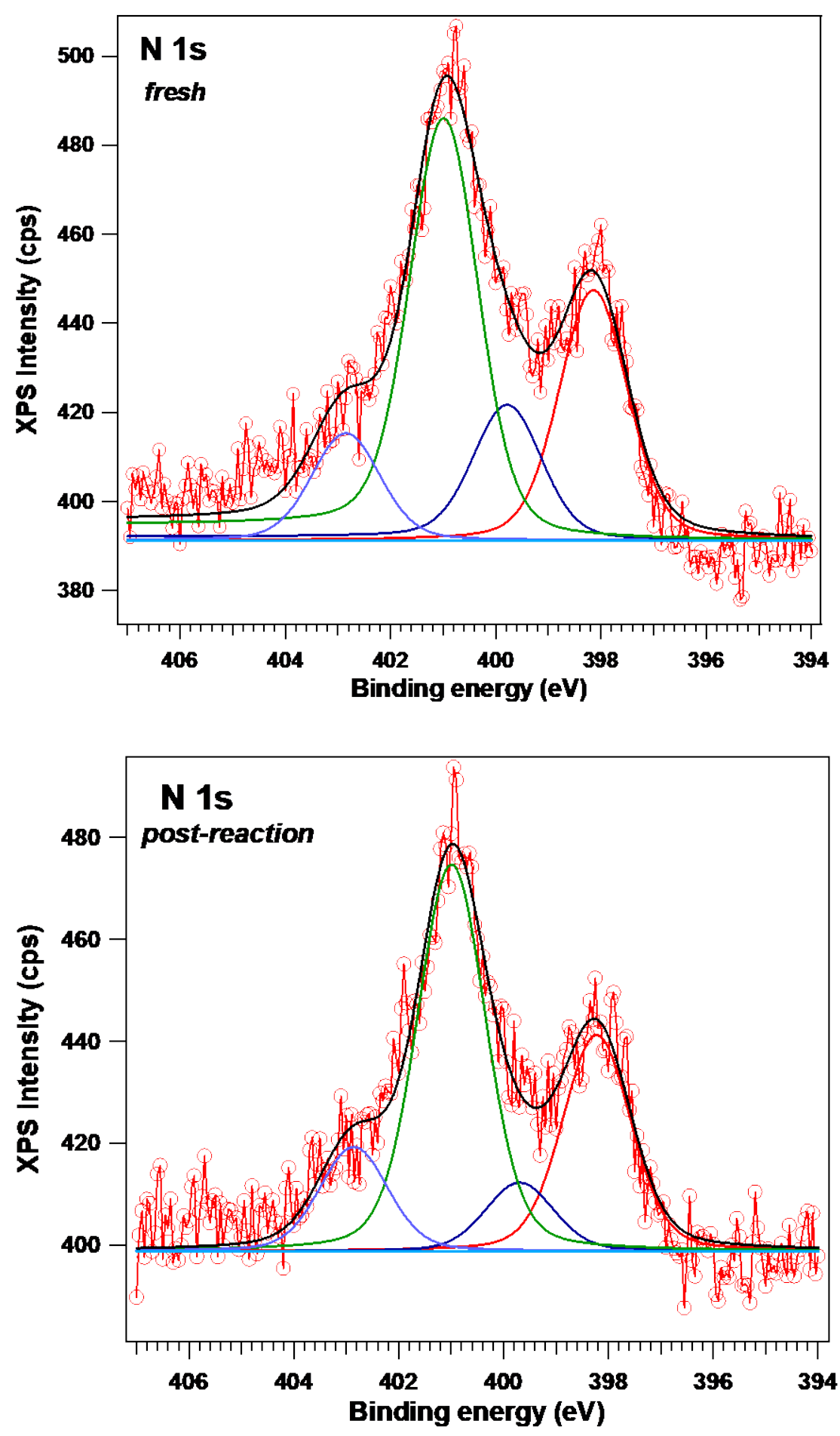

Figure 2. XPS Spectra of the investigated (N)G catalyst in fresh (a) and post-reaction state (b). 


\section{Catalytic tests}

Catalytic performance of the $(\mathrm{N}) \mathrm{G}$ as base was checked in two $\mathrm{C}-\mathrm{C}$ coupling reactions having different reaction mechanisms, such as Michael (Scheme 2, Eq. 1a and 1b) or Henry additions (Scheme 2, Eq. 2). Michael addition reactions were screened electing methyl acetoacetate (MeOAcAc), ethyl acetoacetate (EtOAcAc), isobutyl acetoacetate (i-BuOAcAc), ethyl 2oxocyclohexane carboxylate $(\mathrm{EtOCH})$ or ethyl 2-oxocyclopentane carboxylate (EtOCP), as active methylene compounds, and methyl vinyl ketone (MVK) as Michael acceptor. The Henry addition selected as model reaction was the coupling of benzaldehyde with nitromethane to form the corresponding nitroaldol. Michael addition was investigated in water, ethanol and acetonitrile, while for the Henry addition water and isopropyl alcohol were used as solvents.

Table 2 compiles the results achieved for the Michael addition using (N)G as catalyst compared to inorganic bases or organic molecules. As it can be seen there, water is a suitable solvent. It has been reported that certain heterogeneous bases are incompatible with water as solvent. However, this is not the case of $(\mathrm{N}) \mathrm{G}$ as base for the Michael addition, thus, increasing the greenness of the process.

Table 2. Catalytic performance of $(\mathrm{N}) \mathrm{G}$ in the Michael addition of acetoacetates with MVK acceptor $^{\mathrm{a}}$

\begin{tabular}{lcccccc}
\hline Entry & $\begin{array}{c}\text { Michael } \\
\text { donor }\end{array}$ & Catalyst & Solvent & $\begin{array}{c}\text { Conversion } \\
(\%)\end{array}$ & $\begin{array}{c}\text { Selectivity } \\
\text { MA1 } \\
(\mathbf{\%})\end{array}$ & $\begin{array}{c}\text { Selectivity } \\
\text { MA2 } \\
(\mathbf{\%})\end{array}$ \\
\hline 1 & $\mathrm{MeOAcAc}$ & $\mathrm{NaOH}$ & $\mathrm{H}_{2} \mathrm{O}$ & 100 & 12.7 & 87.3 \\
2 & $\mathrm{MeOAcAc}$ & $(\mathrm{N}) \mathrm{G}$ & $\mathrm{H}_{2} \mathrm{O}$ & 94.5 & 57.6 & 42.4 \\
\hline 3 & EtOAcAc & $(\mathrm{N}) \mathrm{G}$ & $\mathrm{H}_{2} \mathrm{O}$ & 100 & 75.3 & 24.7
\end{tabular}




\begin{tabular}{lcccccc}
$4^{c}$ & EtOAcAc & $(\mathrm{N}) \mathrm{G}$ & $\mathrm{H}_{2} \mathrm{O}$ & 82.8 & 100 & 0 \\
5 & EtOAcAc & Pyridine & $\mathrm{H}_{2} \mathrm{O}$ & 100 & 40.8 & 59.2 \\
6 & EtOAcAc & Pyrrole & $\mathrm{H}_{2} \mathrm{O}$ & 86.7 & 68.4 & 31.6 \\
7 & EtOAcAc & $(\mathrm{N}) \mathrm{G}$ & $\mathrm{EtOH}$ & 11.3 & 100 & 0 \\
8 & EtOAcAc & $(\mathrm{N}) \mathrm{G}$ & $\mathrm{CH}_{3} \mathrm{CN}$ & nd & nd & nd \\
\hline 9 & $i$-ButOAcAc & $(\mathrm{N}) \mathrm{G}$ & $\mathrm{H}_{2} \mathrm{O}$ & 87.5 & 73.7 & 26.3 \\
$10^{\mathrm{c}}$ & $i$-ButOAcAc & $(\mathrm{N}) \mathrm{G}$ & $\mathrm{H}_{2} \mathrm{O}$ & 81.7 & 76.7 & 23.3 \\
11 & $i$-ButOAcAc & $(\mathrm{N}) \mathrm{G}$ & $\mathrm{EtOH}^{-}$ & 38.3 & 100 & 0 \\
12 & $i$-ButOAcAc & $(\mathrm{N}) \mathrm{G}$ & $\mathrm{CH}_{3} \mathrm{CN}$ & 6.6 & 100 & 0 \\
\hline
\end{tabular}

${ }^{a}$ Reaction conditions: Michael donor: $1 \mathrm{mmol}$; Michael acceptor (MVK): 1.5 mmoles or ${ }^{\mathrm{c}}-1$ mmol; Catalyst: $\mathrm{NaOH}$ : 0,12 mmoles, pyridine or pyrrole: 0.144 mmoles, and (N)G: 5 mg; Time:18 h, room temperature, solvent: $8 \mathrm{ml}$, ${ }^{\mathrm{b}}$ Conversion refers to Michael donor transformation. Conversion and selectivity were determined by GC-MS.

With acetylacetonates the reaction may result in two consecutive additions (Scheme 2, Eq.1a, Table 2): the first addition leads to the formation of the mono adduct (MA1) which can be subsequently undergo deprotonation attacking another MVK molecule with the formation, in the second step, of the MA2 product. (N)G showed comparable conversion as homogeneous $\mathrm{NaOH}$ or pyridine $(\mathrm{pKa}=5.25)$ catalysts (94.5 versus $100 \%$, Table 2 , entries $1,2,3$ and 5), with even better selectivity to MA1 than in the case of $\mathrm{NaOH}(12.7 \%$, Table 2, entry 1$)$ and pyridine (40.8\%, Table 2, entry 5), indicating that formation of the double addition MA2 product is favored by strong bases. However, $(\mathrm{N}) \mathrm{G}$ as heterogeneous catalyst is an environmentally friendly alternative, since the use of a soluble base produces wastes and needs additional steps for separation from reaction mixtures. 


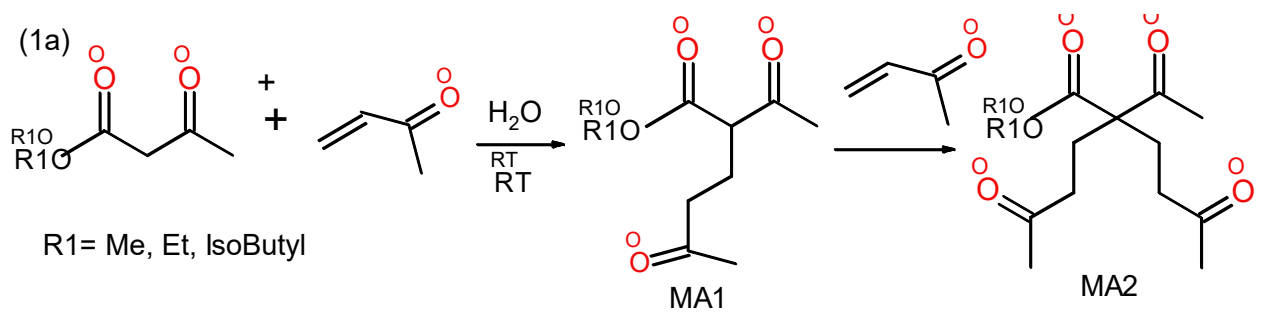

(1b)
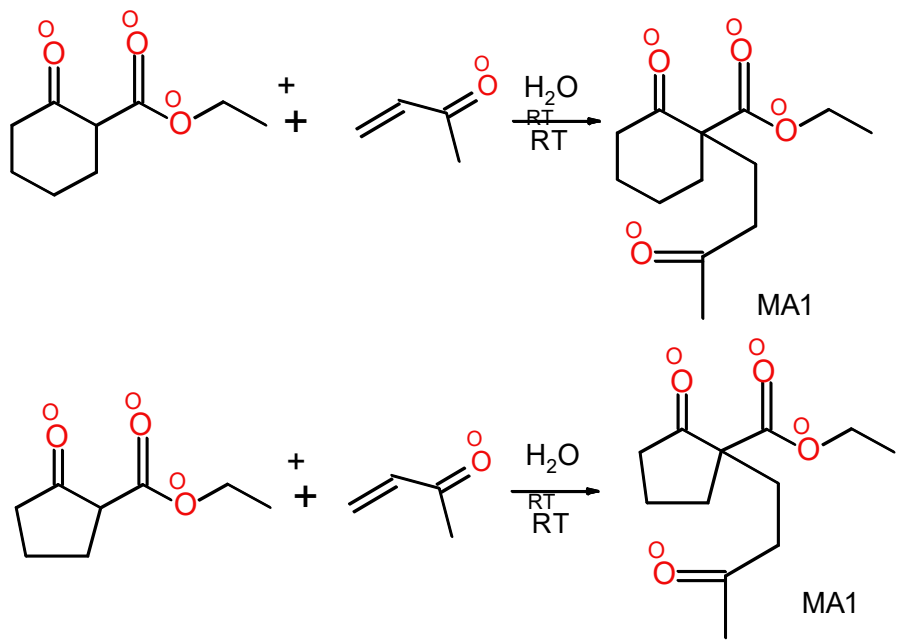

(2)

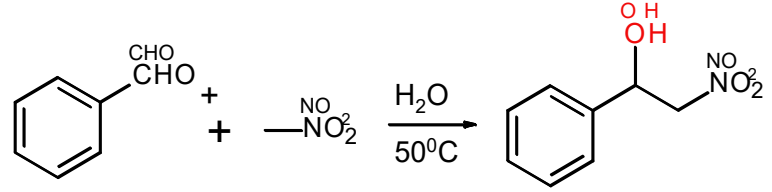

Scheme 2. Michael (1a and 1b) and Henry reaction (2).

Although much less basic than pyridine, and taking into account that $(\mathrm{N}) \mathrm{G}$ contains also a notable $16 \%$ proportion of the total $\mathrm{N}$ atoms similar to pyrrole, the use of pyrrole $(\mathrm{pKa}=-3.8)$ as catalyst to promote the Michael addition was also tested. As it can be seen in Table 2, entry 6, in the presence of pyrrole as catalyst, the Michael addition of MeOAcAc to MVK also takes place, although with a lower conversion $(86.7 \%)$ and a lower selectivity to MA2 product $(31.6 \%)$ than pyridine $(\mathrm{pKa}=5.16)$, in agreement with their relative basicity. $(\mathrm{N}) \mathrm{G}$ as catalyst shows an intermediate behavior between that of pyridine and pyrrole, in agreement with the XPS measurements that shows that $(\mathrm{N}) \mathrm{G}$ contains simultaneously pyridinic and pyrrolic $\mathrm{N}$ atoms in similar proportion as can be observed from Figure 2 ( $a$ and $b$ ). 
The scope of $(\mathrm{N}) \mathrm{G}$ to promote the Michael addition was expanded by screening the activity of cyclic active methylene compounds. Table 3 compiles the results in various solvents of the Michael addition between EtOCH or EtOCP with MVK catalyzed by (N)G. As it can be seen in Scheme 2, equation $1 \mathrm{~b}$, the only possible product in the case of cyclic $\alpha$-ketocarboxylates as substrates is the mono adduct MA1, since these cyclic substrates possess only one $\alpha-\mathrm{H}$ atom.

Table 3. Catalytic performance of $(\mathrm{N}) \mathrm{G}$ in the Michael addition of cyclic compounds ${ }^{\mathrm{a}}$

\begin{tabular}{lllll}
\hline Entry & $\begin{array}{l}\text { Michael } \\
\text { donor }\end{array}$ & Solvent & Conversion $^{\text {b }}$ & $\begin{array}{l}\text { Selectivity MA1 } \\
(\mathbf{1 . 4})\end{array}$ \\
\hline 1 & \multirow{E}{*}{$\mathrm{EtOCH}$} & $\mathrm{H} 2 \mathrm{O}$ & 41.2 & 100 \\
2 & $\mathrm{EtOH}$ & 1.8 & 100 \\
3 & & $\mathrm{CH}_{3} \mathrm{CN}$ & $\mathrm{NR}^{\mathrm{c}}$ & $\mathrm{NR}^{\mathrm{c}}$ \\
\hline 4 & \multirow{2}{*}{$\mathrm{H} 2 \mathrm{O}$} & 100 & 100 \\
5 & & $\mathrm{EtOH}$ & 47.8 & 100 \\
6 & & $\mathrm{CH}_{3} \mathrm{CN}$ & 0.6 & 100 \\
\hline
\end{tabular}

${ }^{a}$ Reaction conditions: Michael donor: 1 mmol: Michael acceptor: 1.5 mmoles, Catalyst: $5 \mathrm{mg}$

(N)G, solvent: $8 \mathrm{~mL}$, room temperature; time: $18 \mathrm{~h}$; ${ }^{\mathrm{b}}$ Conversion refers to Michael donor transformation; ${ }^{\mathrm{c}}$ NR- No reaction

Conversion achieved with the cyclic EtOCP was lower than for the acyclic analogues. The results summarized in Tables 2 and 3 clearly show that water (dipole moment $1.85 \mathrm{D}$ ) is the most suitable solvent for this reaction, providing much higher conversions and selectivity than other tested polar protic solvents $(\mathrm{EtOH}$, dipole moment 1.69 D). As expected in view of the nature of the reaction intermediates involved, less non-polar solvents such as $\mathrm{CH}_{3} \mathrm{CN}$ are not suitable for this type of reaction and conversion values in this solvent are negligible or much lower than for water as reaction medium. 
The second base-catalyzed reaction explored in this study to show the activity of $(\mathrm{N}) \mathrm{G}$ as base was the Henry reaction. Initial experiments were performed in deionized water, as solvent in order to determine the most suitable reaction time for the Henry reaction (Scheme 2, Eq. 2) under the reaction conditions used (Table 4). As Table 4 shows, the yield in nitroaldol increases with the reaction time, achieving a high value conversion (80.2\%) after $24 \mathrm{~h}$. Based on these initial data, a reaction time of $24 \mathrm{~h}$ was selected for further experiments.

Table 4. Variation of nitroaldol yield as a function of time for the Henry addition of nitromethane to benzaldehyde. ${ }^{\mathrm{a}}$

\begin{tabular}{lcc}
\hline Entry & $\begin{array}{c}\text { Time } \\
\text { (h) }\end{array}$ & $\begin{array}{c}\text { Yield to nitroaldol } \\
\text { (\%) }\end{array}$ \\
\hline 1 & 2 & 11.2 \\
2 & 4 & 25.3 \\
3 & 8 & 56.3 \\
4 & 12 & 58.5 \\
5 & 20 & 74.0 \\
6 & 24 & 80.2 \\
\cline { 2 - 2 } Reaction conditions: 0.5 mmoles benzaldehyde, 10 & mmoles $\mathrm{CH}_{3} \mathrm{NO}_{2}$, temperature: $50^{0} \mathrm{C}$, \\
solvent: $3 \mathrm{~mL}$ deionized $\mathrm{H}_{2} \mathrm{O}$, catalyst: $5 \mathrm{mg}$ of $(\mathrm{N}) \mathrm{Gs}$.
\end{tabular}

Table 5 presents the performance at $24 \mathrm{~h}$ of inorganic and organic catalysts compared to that of $(\mathrm{N}) \mathrm{G}$ at different temperatures and in various solvents. In accordance with Bosica et al. [34], $\mathrm{K}_{2} \mathrm{CO}_{3}$ as base is able to promote the Henry addition of nitromethane to benzaldehyde in the absence of other solvent, reaching a high yield to nitroaldol (54.9\%, Table 5, entry 1$)$ with a TON value $2.7 \times 10^{4}$. Unfortunately, the use of $\mathrm{K}_{2} \mathrm{CO}_{3}$ as catalyst requires additional steps for neutralization of this base and separation of the product. Besides $\mathrm{K}_{2} \mathrm{CO}_{3}$ and as in the case of Michael addition, Table 5 entries 4 and 5 shows that solutions of pyridine and pyrrole in isopropyl alcohol (IPA) are also able to catalyze the Henry addition, although with low yields. In 
agreement with their relative basic strength, pyridine is more efficient catalyst than pyrrole, with TON values calculated of $5.6 \times 10^{4}$ for pyridine compared to $1 \times 10^{4}$ for pyrrole.

Table 5. Influence of the nature of the catalyst and solvent in the yield of the Henry reaction between nitromethane and benzaldehyde. ${ }^{\mathrm{a}}$

\begin{tabular}{l|c|c|c|c|c|c}
\hline Entry & Solvent & Catalyst & $\begin{array}{c}\text { Yield in } \\
\text { nitroaldol } \\
\mathbf{( \% )}\end{array}$ & $\begin{array}{c}\text { Moles of } \\
\text { nitrogen x 10 }\end{array}$ & TON $^{\mathrm{b}}$ & $\begin{array}{c}\text { TOF } \\
\mathbf{h}^{\mathbf{1}} \mathbf{)}\end{array}$ \\
\hline $1^{\mathrm{c}}$ & - & $\mathrm{K}_{2} \mathrm{CO}_{3}$ & 54.9 & - & 76.0 & 3.11 \\
2 & $\mathrm{IPA}$ & - & $\mathrm{NR}$ & 1 & - & - \\
3 & $\mathrm{IPA}$ & $(\mathrm{N}) \mathrm{G}$ & 32.2 & 166.0 & 6.91 \\
$4^{\mathrm{d}}$ & $\mathrm{IPA}$ & Pyridine & 8.1 & 144 & 40.5 & 1.68 \\
$5^{\mathrm{e}}$ & $\mathrm{IPA}$ & Pyrrole & 1.5 & 144 & 7.5 & 0.31 \\
6 & $\mathrm{H}_{2} \mathrm{O}$ & - & $\mathrm{NR}^{\mathrm{f}}$ & - & - & - \\
7 & $\mathrm{H}_{2} \mathrm{O}$ & $(\mathrm{N}) \mathrm{G}$ & 80.2 & 1 & 401.0 & 16.71 \\
\hline
\end{tabular}

${ }^{a}$ Reaction conditions: 10 mmoles $\mathrm{MeNO}_{2}, 0.5$ mmoles benzaldehyde, time: $24 \mathrm{~h}$, temperature: $50{ }^{\circ} \mathrm{C}$; solvent: $3 \mathrm{~mL} ; 5 \mathrm{mg}$ catalyst; ${ }^{\mathrm{b}}$ Turnover number (TON) values as moles of benzaldehyde converted per number of basic sites or moles of catalyst (for a homogeneous catalyst); ${ }^{\mathrm{c}} 5 \mathrm{mg}$ $\mathrm{K}_{2} \mathrm{CO}_{3},{ }^{\mathrm{d}} 0.144 \mathrm{mmol}$ of pyridine, ${ }^{\mathrm{e}} 0.144 \mathrm{mmol}$ of pyrrole or $5 \mathrm{mg}(\mathrm{N}) \mathrm{G} ;{ }^{\mathrm{f}} \mathrm{NR}-$ no reaction.

(N)G shows a remarkable catalytic activity to promote the Henry addition. The best results were obtained using $(\mathrm{N}) \mathrm{G}$ as catalyst in $\mathrm{H}_{2} \mathrm{O}$ as solvent (80.2\%, Table 5, entry 7), reaching a nitroaldol yield of $80.2 \%$ and a TON value of $9.8 \times 10^{4}$, based on the amount of basic sites titrated by TPD- $\mathrm{CO}_{2}$. This catalytic performance of $(\mathrm{N}) \mathrm{G}$ in $\mathrm{H}_{2} \mathrm{O}$ was higher than using isopropyl alcohol (IPA), where the TON value was $3.9 \times 10^{4}$, clearly showing the beneficial influence of solvent polarity on the Henry addition. 
At the end of the reaction, the $(\mathrm{N}) \mathrm{G}$ catalyst can be easily recovered by centrifugation and reused for five cycles without any loss of catalytic activity for both coupling reactions.

\section{DFT calculations}

Michael addition of MeOAcAc as nucleophile occurs via $\alpha-\mathrm{H}$ deprotonation, this was the first step taken into consideration. Density functional theory (DFT) calculations were used to predict the stability of different doped $\mathrm{N}$ structures by calculating their formation energy and activity by evaluation of the adsorption and $\alpha-\mathrm{H}$ dehydrogenation activation energies $(\mathrm{C}-\mathrm{H}$ bond breaking) of MeOAcAc molecule. Figure SI 1 depict the investigated nitrogen sites (free pyridinic, pyridinium $\left(\mathrm{N}_{\mathrm{Py}} \mathrm{N}_{\mathrm{PyH}}\right)$, pyrrole $\left(\mathrm{N}_{\mathrm{Pyr}}\right)$ and graphitic $\left(\mathrm{N}_{\mathrm{G}}\right)$ nitrogen). The nitrogen adjacent carbon atoms sites were investigated as well.

The adsorption energy of hydrogen on these sites was evaluated in order to relate the hydrogen binding affinity with the $\mathrm{C}-\mathrm{H}$ bond breaking activation energy. The formation energy values $\left(E_{f}\right.$ in Table SI 1) indicate that the most stable models are those with doped edges $N_{P y}$ in $(\mathrm{N}) \mathrm{G}_{\mathrm{a}}$ and $\mathrm{N}_{\mathrm{PyH}}$ in $(\mathrm{N}) \mathrm{G}_{\mathrm{z}}$. Therefore, it is predicted that the $\mathrm{N}$ atoms in $(\mathrm{N}) \mathrm{G}$ should be preferentially located at the edges of the graphene sheets compared to the basal planes, with higher concentration in the case of zigzag than in the armchair configuration of the periphery, due to larger energy differences estimated for the models with $\mathrm{N}$ atoms at edges respect to the basal plane. This preferential location of $\mathrm{N}$ atoms has been already experimentally confirmed in previous works $[35,36]$. However, it is clear that besides thermodynamic considerations, the distribution of the $\mathrm{N}$ atoms at the edges or on the basal plane has to be determined in a large extent by kinetic reasons related to the structure of the precursor of $(\mathrm{N}) \mathrm{G}$, preparation method and conditions. 
MeOAcAc was chosen as a representative model molecule to investigate the interaction of the nucleophile in the Michael addition with the surface of the various model sites considered for N-doped graphene. Figure 3 shows the most stable adsorption structures of MeOAcAc at the edges of $(\mathrm{N}) \mathrm{G}$.
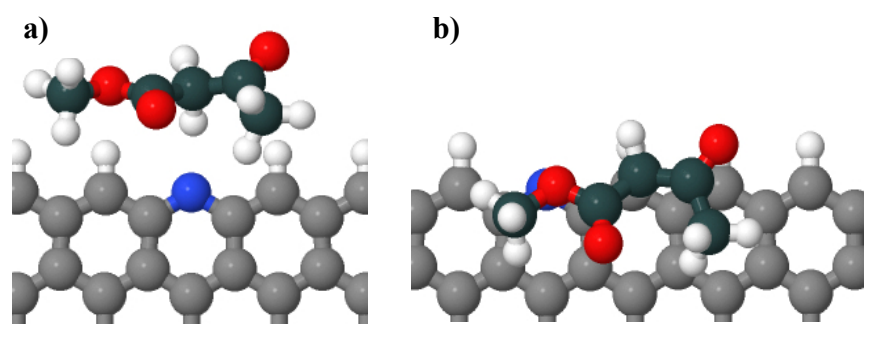

Figure 3. Schematic top views of the most stable adsorption configuration of MeOAcAc at the edges of $(\mathrm{N}) \mathrm{G}$ a) pyridinic $\mathrm{N}$ on $(\mathrm{N}) \mathrm{Gz}$, b) saturated $\mathrm{C}$ edge.

Two adsorption geometries are dependent on the saturation of the edge sites. For free $\mathrm{N}$ sites, the molecule adsorbs aside the sheet, parallel to the edge, with the $\alpha-\mathrm{H}$ pointing to $\mathrm{N}$ (Figure 3a shows the case of the $\mathrm{N}_{\mathrm{Py}}$ site). When the edge sites are saturated, the molecule binds above the surface with $\alpha-\mathrm{H}$ pointing to the binding center (Figure $3 \mathrm{~b}$ shows the case of saturated carbon edge). The adsorption energies calculated at the RPBE level for the adsorption of MeOAcAc on the models of the various $\mathrm{N}$ atoms on $(\mathrm{N}) \mathrm{G}$ are plotted in Figure 3 ( $\square$ ). On free sites MeOAcAc binds weakly (eg. $\Delta \mathrm{E}_{\mathrm{ads}, \mathrm{MeOAcAc}, \mathrm{NPy},(\mathrm{N}) \mathrm{Gz}, \mathrm{RPBE}}=-0.25 \mathrm{eV}$ ), while on saturated sites on both types of $(\mathrm{N}) \mathrm{G}_{\mathrm{a} / \mathrm{z}}$ no binding was determined at this level of theory $\left(\Delta \mathrm{E}_{\mathrm{ads}, \mathrm{RPBE}, \mathrm{MeOAcAc},(\mathrm{N}) \mathrm{Ga} / \mathrm{z}}>0\right)$. However the adsorption energy values vary slightly from one site to another. On $(\mathrm{N}) \mathrm{G}_{\mathrm{a}}, \mathrm{MeOAcAc}$ binds slightly weaker $\left(\Delta \mathrm{E}_{\mathrm{ads}, \mathrm{PBE}, \mathrm{MeOAcAc}} \approx 0.4 \mathrm{eV}\right)$ than on $(\mathrm{N}) \mathrm{G}_{\mathrm{z}}\left(\Delta \mathrm{E}_{\text {ads,RPBE,MeOAcAc }} \approx 0 \mathrm{eV}\right)$. 
The previous calculations based on RPBE were refined by taking into account dispersive forces. The BEEF-vdW correction was applied for the structures that bind aside and for two structures that bind on top of the sheet. When MeOAcAc binds aside, the magnitude of the dispersion forces diminishes $(0.1-0.2 \mathrm{eV})$ compared to the case when this reagent binds on top of the basal plane $(\approx 0.3 \mathrm{eV})$. For the rest of the sites considered MeOAcAc binds above the surface (edge and basal plane). In these other cases, the adsorption energies calculated at RPBE level were corrected by a value of $0.3 \mathrm{eV}$, to account for the effect of the dispersion forces. The adsorption energies after considering the BEEF-vdW correction in each case are plotted also (Figure 4 (口)).

The correction for dispersion forces indicates that adsorption energy values are always favorable thus confirming a weak physisorption of the MeOAcAc molecule regardless the model of the site considered. For all the sites the weak adsorption energies estimated for the two surface models show only slight variations when moving from one adsorption site to another. This does not allow a safe assignment of a site model as the most active site responsible for the catalytic activity of $(\mathrm{N}) \mathrm{G}$ in the Michael reaction.

For a range of solid catalysts, including also modified graphene structures, hydrogen affinity $(\mathrm{EH})$ is a suitable descriptor for the reactivity of the material in hydrocarbon activation of the $\mathrm{C}-\mathrm{H}$ bond $[37,38]$. Thus, reported calculations have indicated a scaling correlation between the hydrogen affinity and the activation energy of the $\mathrm{C}-\mathrm{H}$ bond in methane, ethane and methanol [39]. On this basis we have explored the adsorption energy of hydrogen ( $\left.\Delta \mathrm{E}_{\mathrm{ads}, \mathrm{RPBE}, \mathrm{H}}\right)$ as a possible descriptor for the deprotonation of the $\alpha-\mathrm{H}$ position of MeOAcAc in active methylene compounds on the edge and basal plane of the studied $(\mathrm{N}) \mathrm{G}_{\mathrm{z} / \mathrm{a}}$ structures. RPBE 
values were used to estimate the hydrogen adsorption energy because the magnitude of dispersion forces for the hydrogen atom is negligible.

The adsorption energies of $\mathrm{H}$ on $(\mathrm{N}) \mathrm{G}_{\mathrm{a}}$ and $(\mathrm{N}) \mathrm{G}_{\mathrm{z}}$ are plotted in Figure $4(\mathbf{a})$ as well. Compared to the binding energy for $\mathrm{MeOAcAc}$, hydrogen adsorption energy values vary in higher magnitude when passing from one site to another. On $(\mathrm{N}) \mathrm{G}_{\mathrm{a}}$ the site that binds the $\mathrm{H}$ atom stronger is the carbon atom at the edge adjacent to $\mathrm{N}_{\mathrm{PyH}}(-0.28 \mathrm{eV})$, followed by the $\mathrm{N}_{\mathrm{Py}}(0.07$ $\mathrm{eV})$. This is good evidence that the presence of $\mathrm{N}$ as dopant changes the reactivity of the $\mathrm{C}$ edge. Such a behavior has already been confirmed for oxygen reduction reactions [40]. The other investigated sites, including those on pristine graphene, show no binding affinities and its adsorption energy decrease progressively. Correlation with the weak binding energy of MeOAcAc indicate for most of the $(\mathrm{N}) \mathrm{G}_{\mathrm{a}}$ sites no activity towards the deprotonation should be expected. 

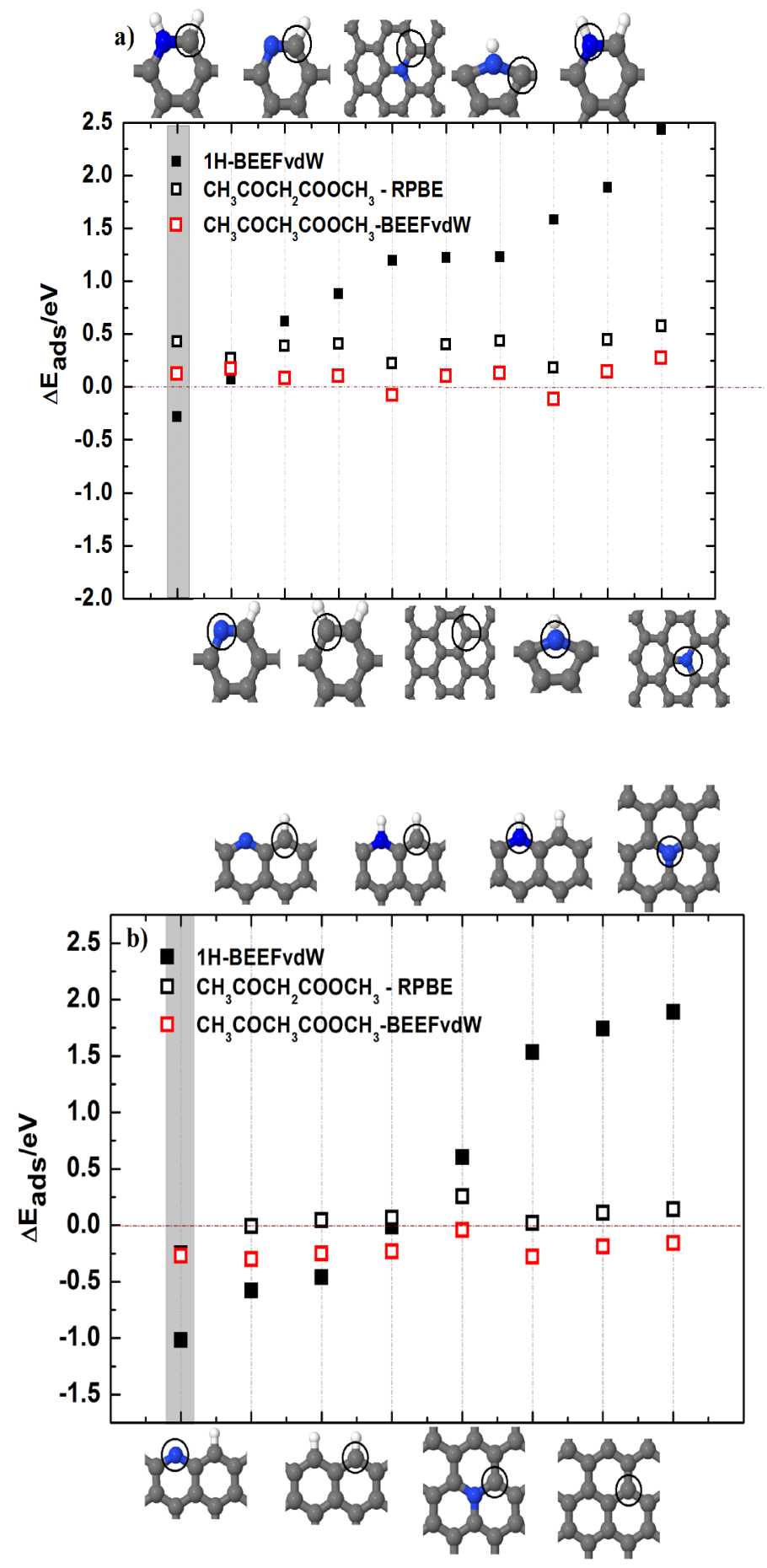

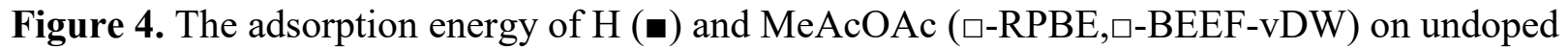
and N-doped graphene a) armchair $(\mathrm{N}) \mathrm{G}_{\mathrm{a}}$ b) zigzag $(\mathrm{N}) \mathrm{G}_{\mathrm{z}}$. Above and below each graph is the schematic top view of binding sites marked by the black circle. 
On $(\mathrm{N}) \mathrm{G}_{\mathrm{z}}$ (Figure $\left.4 \mathrm{~b}\right), \mathrm{N}_{\mathrm{Py}}(-1.02 \mathrm{eV})$ affords the strongest bond with $\mathrm{H}$. Then, the affinities towards $\mathrm{H}$ varies in the following order: the $\mathrm{C}$ (coordinated with $\mathrm{H}$ ) site from the edge adjacent to $\mathrm{N}_{\text {Py }}(-0.58 \mathrm{eV})>\mathrm{C}$ site of the undoped ribbon $(-0.46 \mathrm{eV})>\mathrm{C}$ site neighbor to $\mathrm{N}_{\text {PyH }}(-$ $0.01 \mathrm{eV})$. The other studied sites show no binding affinity towards hydrogen as confirmed by a progressive increase of the adsorption energy. The less active sites are $\mathrm{N}_{\mathrm{G}}$ and the graphitic $\mathrm{C}$ from undoped ribbon. These data suggest the undoped edge of graphene can have also some activity in deprotonation.

Overall, it can concluded that the edge sites of both structures present higher affinities towards hydrogen compared to basal plane, with the $\mathrm{N}$ free sites having among the highest affinities. The $\mathrm{C}$ edge of undoped zigzag edges show a comparable affinity with the doped one, while the $\mathrm{C}$ edge site of $(\mathrm{N}) \mathrm{G}_{\mathrm{a}}$ is activated by nitrogen doping compared to the same $\mathrm{C}$ site of undoped structure. Higher activities of doped edge sites were also evidenced for oxygen reduction reactions requiring basic sites ${ }^{41}$. Also, studies indicate the activity of $\mathrm{C}$ sites next to $\mathrm{N}$ sites in doped graphene and also the edge sites of zigzag undoped grapheme [41-43].

Therefore, according to the calculations it seems that $\mathrm{N}_{\text {Py }}$ sites, particularly at the zig-zag edges, are those exhibiting notable $\mathrm{H}$ adsorption energy and existing in a substantial proportion in the XPS analysis. Further, we have selected the structures of $(N) G_{a}$ and of $(N) G_{z}$ that show the highest affinity for hydrogen to investigate the activation energies for hydrogen subtraction from MeOAcAc ( $\alpha-\mathrm{C}-\mathrm{H}$ bond breaking) (see in Figure SI 1 for the potential energy diagrams corresponding to the four structures). For this purpose, we have selected supplementary structures: i) with the lowest hydrogen affinity and ii) with affinities in between the highest and lowest ones to picture the trend between hydrogen binding energy as descriptor and C-H bond breaking activation energies. For all the studied systems the $\mathrm{C}-\mathrm{H}$ bond breaking reaction energy 
is endothermic $\left(\Delta \mathrm{E}_{\mathrm{r}}>0\right)$. The lowest activation and reaction energies were obtained for $\mathrm{N}_{\mathrm{Py}}$ site of both $(\mathrm{N}) \mathrm{G}_{\mathrm{z}}\left(\Delta \mathrm{E}_{\mathrm{r}, \mathrm{C}-\mathrm{H}}=0.2 \mathrm{eV}, \Delta \mathrm{E}_{\mathrm{a}, \mathrm{C}-\mathrm{H}}=0.62 \mathrm{eV}\right)$ and $(\mathrm{N}) \mathrm{G}_{\mathrm{a}}\left(\Delta \mathrm{E}_{\mathrm{r}, \mathrm{C}-\mathrm{H}}=0.53 \mathrm{eV}, \Delta \mathrm{E}_{\mathrm{a}, \mathrm{C}-\mathrm{H}}=0.6\right.$ $e V)$. Relatively low energies are also calculated for $C$ sites on the edge of free $(N) G_{z}, C$ site adjacent of $\mathrm{N}_{\mathrm{Py}}$ of $(\mathrm{N}) \mathrm{G}_{\mathrm{z}}$ and $\mathrm{N}_{\mathrm{PyH}}$ of $(\mathrm{N}) \mathrm{G}_{\mathrm{a}}$ (see Figure SI $2-\Delta \mathrm{E}_{\mathrm{r}, \mathrm{C}-\mathrm{H}} \approx 0.6 \mathrm{eV}, \Delta \mathrm{E}_{\mathrm{a}, \mathrm{C}-\mathrm{H}} \approx 1 \mathrm{eV}$ ). For the other structures both the reaction and activation energies increase progressively to $\approx 3 \mathrm{eV}$ (See Table SI 2).

The activation energy values have been used to check the linear dependence on the hydrogen binding energy as descriptor. As it can be seen in Figure 5, the relation between $\Delta \mathrm{E}_{\mathrm{H}}$ and $\Delta \mathrm{E}_{\mathrm{a}, \mathrm{C}-\mathrm{H}}$ in MeOAcAc follow a scaling relationship $\left(\Delta \mathrm{E}_{\mathrm{a}, \mathrm{C}-\mathrm{H}}=0.77 \Delta \mathrm{E}_{\mathrm{H}}+1.38\right)$ similar with previously established for $\mathrm{C}-\mathrm{H}$ dissociation (methane, ethane, and methanol) via radical pathway on various substrates [26]. This relation can be also applied to other graphene materials (eg. different size nitrogen doped graphene models) or to other types of materials thus avoiding computational expensive calculations.

Therefore, calculations considering two surface models with various types of $\mathrm{N}$ atoms indicate that the TS energy increases with increase of the binding energy of hydrogen. These computational results are in line with the obtained catalytic results. 


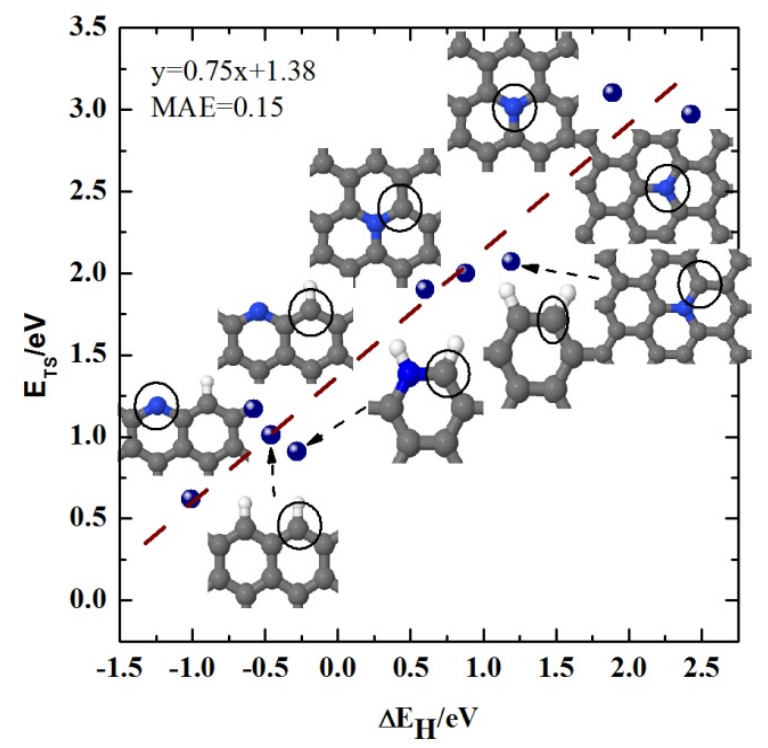

Figure 5. Scaling relation between hydrogen binding energy and activation energy of dehydrogenation $\left(0.77 \Delta \mathrm{E}_{\mathrm{H}}+1.37, \mathrm{MAE}=0.17\right)$

Water appears to be a suitable solvent to achieve high conversions in both reactions. Obviously, since the reaction takes place in aqueous phase, the initial distribution of $\mathrm{N}$ atoms is affected due to the easy protonation of the $\mathrm{N}_{\mathrm{Py}}$ to $\mathrm{N}_{\mathrm{PyH}}$ sites by water. As an effect of this protonation, $\mathrm{C}$ sites at the edge adjacent of $\mathrm{N}_{\text {PyH }}$ with appropriate reactivity towards the $\alpha-\mathrm{C}-\mathrm{H}$ bond breaking are formed. As a general consequence, the overall catalytic efficiency of the carbo-catalyst was highly improved.

To the best of our knowledge there are no previous reports related to water interaction with the nitrogen-doped graphene sites, concluding the protonation of the sites [37]. It was shown by XP spectroscopy that after the oxygen reduction in acidic conditions, HO fragments become attached to the $\mathrm{C}$ atoms directly coordinated to pyridinic $\mathrm{N}$. The DFT calculations performed in this study focused on water adsorption and dissociation on the most basic site of $(N) G_{z}$, ie $N_{\text {Py. }}$ These calculations indicate that $\mathrm{H}_{2} \mathrm{O}$ adsorbs above the nitrogen site with the $\mathrm{H}$ pointing towards $\mathrm{N}_{\text {Py. }}$. 
The adsorption energy (-0.28 eV (at BEEF-vdW level and $-0.23 \mathrm{ev}$ at RPBE level)) is similar with that of MeOAcAc on the same site. However, the dissociation is possible only through a coadsorption of $\mathrm{HO}$ on the $\mathrm{C}$ neighboring site. The dissociated form is much less stable than the undissociated one $\left(\Delta \mathrm{E}_{\mathrm{r}, \mathrm{H}-\mathrm{O}}=1.53 \mathrm{eV}\right.$, see Figure SI 3), while the activation energy is much higher than in the case of MeOAcAc $\left(\Delta \mathrm{E}_{\mathrm{a}, \mathrm{H}-\mathrm{O}}=1.8 \mathrm{eV}\right)$. Accordingly, the activation energy for $\mathrm{H}-\mathrm{O}$ dissociation is much higher than the activation energy of $\alpha-\mathrm{H}-\mathrm{C}$ bond breaking.

These calculations are in line to the ATR spectra of $(\mathrm{N}) \mathrm{G}$ in the presence of the different solvents (Figure 6, a). While the typical bands of the organic solvents shift the position and decrease in the intensity, no change in the spectra of water was evidenced. For the organic solvents the new bands were assigned to either chelated $\mathrm{OH}\left(2885 \mathrm{~cm}^{-1}\right.$ for ethanol) or $\mathrm{CCN}$ bend $\left(2360 \mathrm{~cm}^{-1}\right.$ for AcCN). The ATR spectrum of the humid $(\mathrm{N}) \mathrm{G}$ presents only bands associated with water. These bands disappear after drying of the sample, confirming both the stability of (N)G and the very weak interaction (adsorption) with water. It is also known that due to this behaviour, wetting graphene offers a safe way to transport it [44].

Thus, these spectroscopic data indicate that water is not competing with the substrate in the catalytic reaction. Contrarily, the organic solvents adsorb on $(\mathrm{N}) \mathrm{G}$, thus, limiting the reaction rate (Table 5).

Calculation of the activation energy for the Henry reaction between nitromethane and benzaldehyde onto the (N)G catalyst in the range from RT (TOFs of $6.91 \mathrm{~h}^{-1}$ for IPA and 11.38 $\mathrm{h}^{-1}$ for $\mathrm{H}_{2} \mathrm{O}$ ) till $80{ }^{\circ} \mathrm{C}$ (TOFs of $16.71 \mathrm{~h}^{-1}$ for IPA and $22.4 \mathrm{~h}^{-1}$ for $\mathrm{H}_{2} \mathrm{O}$ ) gave an additional confirmation for effect of the solvent. Thus, the activation energy calculated for the reaction carried out in IPA was of $34.18 \mathrm{~kJ} / \mathrm{mol}$, ie, higher when compared to the activation energy of $20.4 \mathrm{~kJ} / \mathrm{mol}$ calculated for water. 


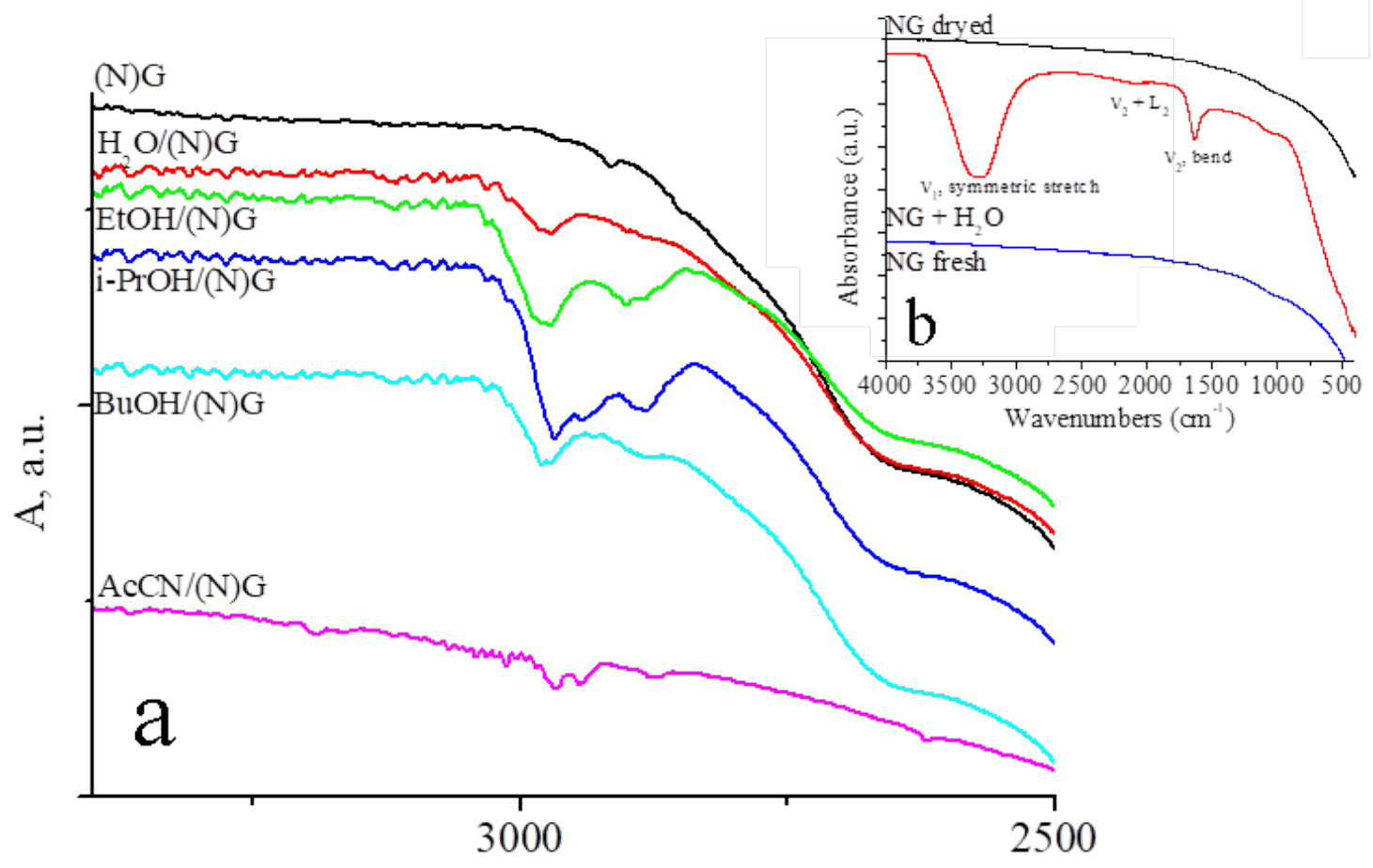

Wavenumbers, $\mathrm{cm}^{-1}$

Figure 6. ATR spectra collected for $(\mathrm{N}) \mathrm{G}$ in the presence of the different solvents (a) and for fresh and wet $(\mathrm{N}) \mathrm{G}(\mathrm{b})$

\section{CONCLUSIONS}

Acid-base titrations using $\mathrm{NH}_{3}$ and $\mathrm{CO}_{2}$ probe molecules indicated that defective $\mathrm{N}$ doped graphene has considerable more density of basic than acid sites. Also the strength of the sites, determined based on the desorption temperature, for basic sites is higher than the less abundant acid sites. The catalytic activity of $\mathrm{N}$-doped graphene as base has been proved here by using two classical $\mathrm{C}-\mathrm{C}$ bond forming organic reactions of large importance in synthesis that require basicity, such as the Michael and Henry additions. For both $\mathrm{C}-\mathrm{C}$ forming reactions, water was found a suitable solvent, thus, increasing the appeal of the process. DFT calculations indicate as the most active sites that are present in the material are pyridinic nitrogen, particularly 
those at zigzag edges, but also the $\mathrm{C}$ sites of doped and undoped zigzag edges, $\mathrm{C}$ adjacent to the protonated nitrogen on armchair edge. Based on this calculations, the positive effect of water can be explained through the protonation of pyridinic nitrogen. In turn, these protonated pyridinic nitrogen sites activate the adjacent $\mathrm{C}$ sites, with an appropriate reactivity towards the $\alpha-\mathrm{C}-\mathrm{H}$ bond breaking. $\mathrm{H}$ adsorption energy is proposed as a simple descriptor to establish the relative basic strength and catalytic activity of the various possible sites in different graphenes. Water exhibits a weak interaction with the surface mainly providing the role of the solvent, as confirmed by the ATR spectra. Such a behaviour is responsible for the higher TON/TOFs calculated for this solvent.

\section{ASSOCIATED CONTENT}

\section{Supporting Information.}

The Supporting Information is free of charge on the ACS Publication website at DOI:

DFT calculated formation energies, potential energy, activation and reaction energies for methylacetoacetate molecule on doped and undoped graphene

\section{AUTHOR INFORMATION}

\section{Corresponding Author}

* Prof. Hermenegildo Garcia, hgarcia@qim.upv.es

\section{Author Contributions}

The manuscript was written through contributions of all authors. All authors have given approval to the final version of the manuscript. 


\section{Notes}

The authors declare no competing financial interest

\section{ACKNOWLEDGMENT}

This work was supported by UEFISCDI (PN-III-P4-ID-PCE-2016-0146, nr. 121/2017 and

project number PN-III-P1-1.1-TE-2016-2191, nr. 89/2018). Financial support by the Spanish

Ministry of Economy and Competitiveness (Severo Ochoa and CTQ2015-69653-CO2-R1) and

Generalitat Valenciana (Prometeo 2017-083) is gratefully acknowledged. A.P thanks the Spanish

Ministry of Science and Innovation for a Ramón y Cajal research associate contract.

\section{REFERENCES}

1. G. Bottari, M. Á. Herranz, L. Wibmer, M. Volland, L. Rodríguez-Pérez, D. M. Guldi, A. Hirsch, N. Martín, F. D'Souza and T. Torres, Chem. Soc. Rev., 2017, 46, 4464-4500.

2. $\quad$ S. Park and R. S. Ruoff, Nature Nanotech., 2009, 4, 217.

3. C. Huang, C. Li and G. Shi, Energ. Environ. Sci., 2012, 5, 8848-8868.

4. S. Navalon, A. Dhakshinamoorthy, M. Alvaro and H. Garcia, Chem. Rev., 2014, 114, 6179-6212.

5. D. S. Su, S. Perathoner and G. Centi, Chem. Rev., 2013, 113, 5782-5816.

6. A. Bostwick, F. Speck, T. Seyller, K. Horn, M. Polini, R. Asgari, A. H. MacDonald and E. Rotenberg, Science, 2010, 328, 999-1002.

7. X.-K. Kong, C.-L. Chen and Q.-W. Chen, Chem. Soc. Rev., 2014, 43, 2841-2857.

8. X. Wang, X. Li, L. Zhang, Y. Yoon, P. K. Weber, H. Wang, J. Guo and H. Dai, Science, 2009, 324, 768-771.

9. $\quad$ Z. Jin, J. Yao, C. Kittrell and J. M. Tour, ACS Nano, 2011, 5, 4112-4117.

10. Z. Sun, Z. Yan, J. Yao, E. Beitler, Y. Zhu and J. M. Tour, Nature, 2010, 468, 549.

11. H. Wang, T. Maiyalagan and X. Wang, ACS Catal., 2012, 2, 781-794.

12. R. Yadav and C. K. Dixit, J. Sci.: Adv. Mater. Devices, 2017, 2, 141-149.

13. Z. Lin, G. Waller, Y. Liu, M. Liu and C.-P. Wong, Adv. Energ. Mater., 2012, 2, 884-888.

14. S. van Dommele, K. P. de Jong, J. H. Bitter, Chem. Commun., 2006, 4859-4861.

15. L. Wang, L. Wang, H. Jin, N. Bing, Catal.Commun., 2011, 15, 78-81.

16. N. Kan-nari, S. Okamura, S.-i. Fijita, J.-i. Ozaki, M. Arai, Adv. Synth. Catal., 2010, 352, $1476-1484$.

17. X. Jin, V. V. Balasubramanian, S. T. Selvan, D. P. Sawant, M. A. Chari, G. Q. Lu, A. Vinu, Angew. Chem. Intern. Ed., 2009, 48, 7884-7887.

18. P. Perlmutter, Conjugate Addition Reactions in Organic Synthesis, Elmsford, New York, 1992.

19. H. Gangliang and L. Xue, Curr. Org. Synth., 2017, 14, 568-571. 
20. N. Ono, in The Nitro Group in Organic Synthesis, ed. Wiley, New York, 2001, pp. 30-61.

21. K. Akutu, H. Kabashima, T. Seki and H. Hattori, Appl. Catal. A: General, 2003, 247, 6574.

22. R. Ballini, G. Bosica, D. Fiorini, A. Palmieri and M. Petrini, Chem. Rev., 2005, 105, $933-$ 972.

23. B. M. Choudary, C. V. Rajasekhar, G. Gopi Krishna and K. Rajender Reddy, Synth. Commun., 2007, 37, 91-98.

24. V. Georgakilas, Functionalization of Graphene, Wiley, Patras, 2014.

25. J. Enkovaara, C. Rostgaard, J. J. Mortensen, J. Chen, M. Dułak, L. Ferrighi, J. Gavnholt, C. Glinsvad, V. Haikola, H. A. Hansen, H. H. Kristoffersen, M. Kuisma, A. H. Larsen, L. Lehtovaara, M. Ljungberg, O. Lopez-Acevedo, P. G. Moses, J. Ojanen, T. Olsen, V. Petzold, N. A. Romero, J. Stausholm-Møller, M. Strange, G. A. Tritsaris, M. Vanin, M. Walter, B. Hammer, H. Häkkinen, G. K. H. Madsen, R. M. Nieminen, J. K. Nørskov, M. Puska, T. T. Rantala, J. Schiøtz, K. S. Thygesen and K. W. Jacobsen, J. Phys.: Condensed Matter, 2010, 22, 253202.

26. J. J. Mortensen, L. B. Hansen and K. W. Jacobsen, Phys. Rev. B, 2005, 71, 035109.

27. A. H. Larsen, J. J. Mortensen, J. Blomqvist, I. E. Castelli, R. Christensen, M. Dułak, J. Friis, M. N. Groves, B. Hammer, C. Hargus, E. D. Hermes, P. C. Jennings, P. B. Jensen, J. Kermode, J. R. Kitchin, E. L. Kolsbjerg, J. Kubal, K. Kaasbjerg, S. Lysgaard, J. B. Maronsson, T. Maxson, T. Olsen, L. Pastewka, A. Peterson, C. Rostgaard, J. Schiøtz, O. Schütt, M. Strange, K. S. hygesen, T. Vegge, L. Vilhelmsen, M. Walter, Z. Zeng and K. W. acobsen, J. Phys.: Condens. Matter, 2017, 29, 273002.

28. G. Kresse and D. Joubert, Phys. Rev. B, 1999, 59, 1758-1775.

29. S. A. Arrhenius, Z. Phys. Chem., 1889, 4, 96-116.

30. A. Primo, E. Sánchez, J. M. Delgado and H. García, Carbon, 2014, 68, 777-783.

31. A. Primo, P. Atienzar, E. Sanchez, J. M. Delgado and H. García, Chem. Commun., 2012, 48, 9254-9256.

32. D. Lamoen and J. T. Titantah, Diam. Relat. Mater., 2007, 16, 581-588.

33. A. Arenillas, T. C. Drage, K. M. Smith and C. E. Snape, J. Anal. Appl. Pyrol., 2005, 74, 298-306.

34. G. Bosica and K. Polidano, J. Chem., 2017, 2017, Article ID 6267036.

35. J. Jiang, J. Turnbull, W. Lu, P. Boguslawski and J. Bernholc, J. Chem. Phys., 2012, 136, 014702.

36. M. Li, L. Zhang, Q. Xu, J. Niu and Z. Xia, J. Catal., 2014, 314, 66-72.

37. H. Aljama, J. K. Norskov and F. Abild-Pedersen, J. Phys. Chem. C, 2017, 121, 1644016446.

38. A. A. Latimer, H. Aljama, A. Kakekhani, J. S. Yoo, A. Kulkarni, C. Tsai, M. GarciaMelchor, F. Abild-Pedersen and J. K. Norskov, Phys. Chem. Chem. Phys., 2017, 19, 3575-3581.

39. A. A. Latimer, A. R. Kulkarni, H. Aljama, J. H. Montoya, J. S. Yoo, C. Tsai, F. AbildPedersen, F. Studt and J. K. Norskov, Nature Mater., 2016, 16, 225.

40. D. W. Boukhvalov, Y. W. Son and R. S. Ruoff, ACS Catal., 2014, 4, 2016-2021.

41. D. Guo, R. Shibuya, C. Akiba, S. Saji, T. Kondo and J. Nakamura, Science, 2016, 351, 361-365.

42. T. Kondo, S. Casolo, T. Suzuki, T. Shikano, M. Sakurai, Y. Harada, M. Saito, M. Oshima, M. I. Trioni, G. F. Tantardini and J. Nakamura, Phys. Rev. B, 2012, 86, 035436. 
43. Y. Jiang, L. Yang, T. Sun, J. Zhao, Z. Lyu, O. Zhuo, X. Wang, Q. Wu, J. Ma and Z. Hu, ACS Catal., 2015, 5, 6707-6712.

44. C.-N. Yeh, H. Huang, A. T. O. Lim, R.-H. Jhang, C.-H. Chen and J. Huang, Nat. Commun., 2019, 10, 422. 


\section{TABLE OF CONTENTS GRAPHIC}

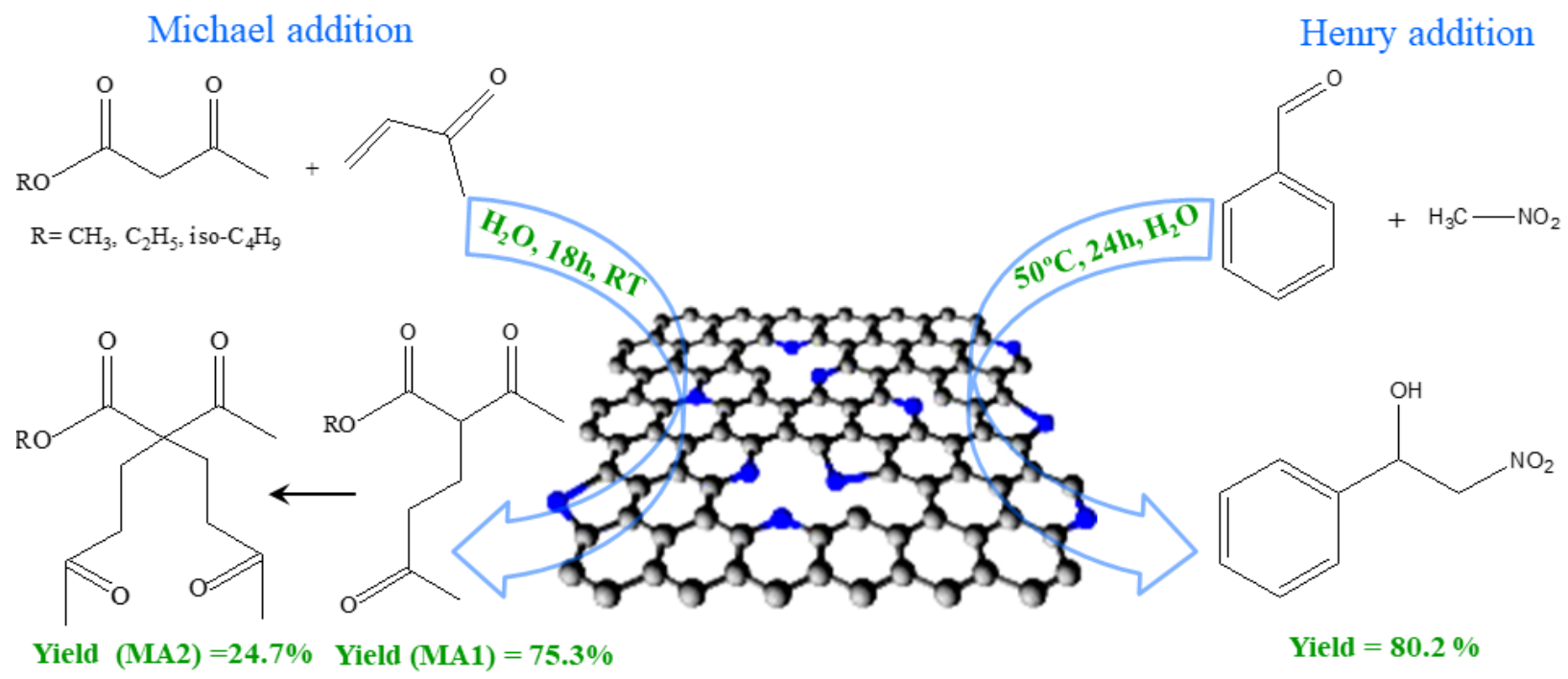

$\mathrm{N}$-doped graphene as metal free catalyst for coupling reactions 